\title{
Partisipasi Petani Dalam Penerapan Pemupukan Berimbang Padi Sawah Di Kecamatan Sindangwangi Majalengka
}

\section{Farmer Participation In The Implementation Of Rice Balanced Fertilizing In Sindangwangi Subdistrict, Majalengka}

\author{
${ }^{1}$ Lukman Effendy, dan ${ }^{2}$ Ruwan Diantoro \\ ${ }^{1,2}$ Politeknik Pembangunan Pertanian (Polbangtan) Bogor \\ Program Studi Penyuluhan Pertanian Berkelanjutan \\ Email: f1515di@gmail.com
}

\begin{abstract}
ABSTRAK
Partisipasi masyarakat adalah salah satu indikator keberhasilan pembangunan, oleh karena itu tingkat partisipasi petani dalam suatu kegiatan atau program penting untuk dipelajari. Penelitian terkait partisipasi dilakukan di Kecamatan Sekarwangi, Kabupaten Majalengka dengan tujuan: (1) mendeskripsikan tingkat partisipasi petani dalam penerapan teknologi pemupukan beras berimbang, (2) menganalisis faktor-faktor terkait partisipasi, ( 3) menemukan strategi untuk meningkatkan partisipasi petani dalam penerapan pemupukan berimbang. Penelitian menggunakan metode survei ini berlangsung selama 3 bulan (April Juni 2018), menggunakan 48 responden dari empat kelompok dari dua desa yang telah berpartisipasi dalam program SLPTT, yaitu kelompok Heuleut yang terdiri dari 13 orang, Mekar Harapan 16 orang, Sawah Maja 10 Orang, dan Teralame 9 orang. Data dikumpulkan dengan teknik wawancara langsung menggunakan kuesioner yang telah diuji validitas dan kelepasannya. Data yang dikumpulkan adalah analisis deskriptif dan korelasi Rank Spearman. Hasil yang diperoleh: (1) sebagian besar (62,5\%) partisipasi petani berada dalam kategori rendah, (2) faktor internal terkait adalah tingkat pendidikan, sedangkan usia dan pengalaman bisnis tidak terkait, (3) faktor eksternal terkait adalah ketersediaan fasilitas produksi, intensitas konseling dan ketersediaan sumber informasi, (4) strategi untuk meningkatkan partisipasi petani dalam penerapan pemupukan berimbang dimulai dan difokuskan pada penyediaan pengetahuan dan pemahaman tentang dosis yang tepat dalam pemupukan.
\end{abstract}

Kata kunci-Partisipasi, Pemupukan Berimbang, Petani, Rank Spearman

\begin{abstract}
Community participation is one indicator of the success of development, hence the level of farmers' participation in an activity or program is important to study. A study related to participation was carried out in Sekarwangi Sub-District, Majalengka Regency with the aim of: (1) describing the level of participation of farmers in the application of balanced rice fertilization technology, (2) analyzing factors related to participation, (3) finding strategies to increase farmers' participation in the application of fertilization balanced. The research using this survey method lasted for 3 months (April - June 2018), using 48 respondents from four groups from two villages who had participated in the SLPTT program, namely the Heuleut group of 13 people, Mekar Harapan 16 people, Sawah Maja 10 People, and Teralame 9 people. Data were collected by direct interview technique using a questionnaire that had been tested for validity and releability. The data collected is
\end{abstract}


descriptive analysis and Rank Spearman correlation. The results obtained: (1) most (62.5\%) farmer participation is in the low category, (2) related internal factors are the level of education, while age and business experience are not related, (3) related external factors are the availability of production facilities, the intensity of counseling and the availability of information sources, (4) strategies to increase farmers' participation in the application of balanced fertilization were started and focused on providing knowledge and understanding of the right dosage in fertilization.

Keywords - Balanced Fertilization, Farmer, Participation, Rank Spearman

\section{PENDAHULUAN}

Upaya untuk meningkatkan produksi khususnya padi sawah telah banyak dilakukan oleh petani, antara lain; dengan penggunaan varietas unggul dan penggunaan pupuk yang direkomendasikan. Penggunaan pupuk khususnya pupuk anorganik sering tidak terkendali sehingga terjadi kelebihan dosis yang berdampak buruk terhadap tekstur dan biologi tanah (Effendy dan Badri. 2020). Salah satu inovasi yang dianjurkan Kementerian Pertanian untuk mengurangi dampak tersebut adalah dengan penggunaan pupuk secara berimbang, Akan tetapi di lapangan inovasi ini belum sepenuhnya diterapkan oleh petani, hasil penelitian Effendy dan Sudiro di Ciamis (2020) menunjukkan, bahwa sebagian besar petani $(86.25 \%)$ masih dalam kategori sedang dalam penerapan teknologi pemupukan secara berimbang. Menurut penelitian yang sama penyebab belum sepenuhnya inovasi pemupukan berimbang karena belum sepenuhnya memahami manfaat dari penggunaan teknologi pemupukan berimbang, karena itu perlu upaya untuk mendorong partisipasi petani padi sawah agar mau menerapkan teknologi pemupukan berimbang secara berkesinambungan. Penelitian serupa yang dilakukan Effendy dan Oktaviansyah di beberapa desa Kecamatan Sindangkasih Ciamis menguji beberapa variabel terhadap partisipasi, yaitu: (1) karakteristik Pribadi yang terdiri atas umur, pendidikn, pengalaman usahatani, dan luas lahan, karakteristik lingkungan meliputi; ketersediaan sarana transportasi, ketersediaan benih, dan persepsi masyarakat, dan (3) dukungan pemerintah yang terdiri atas: peran penyuluhan, bantuan sarana dan prasarana, serta adanya program peningkatan produksi. Hasil penelitian ini menunjukkan bahwa partisipasi petani dalam penggunaan pupuk berimbang masih tergolong rendah.

Perjalanan suatu inovasi diharapkan berakhir dengan adanya adopsi, namun kenyataan di lapangan tidak semua inovasi dengan cepat diadopsi atau diterima oleh masyarakat. Penerapan suatu inovasi atau teknologi diperlukan partisipasi masyarakat yang menjadi sasaran dari sebuah inovasi. Partisipasi merupakan keterlibatan secara fisik dan mental seseoarng terhadap suatu kegiatan atau program (Slamet. 2003), artinya semakin tinggi tingkat keterlibatan seseorang dalam suatu program maka semakin tinggi pula kemungkinan keberhasilan kegiatan atau program yang dilakukan. Berdasarkan asumsi tersebut maka dilakukan penelitian untuk mengkaji partisipasi petani khususnya dalam penerapan teknologi pemupukan berimbang. Penelitian ini secara khusus bertujuan untuk: (1) mendeskripsikan tingkat partisipasi petani dalam penerapan pemupukan berimbang, (2) menganalisis faktor yang berhubungan dengan partisipasi, dan (3) merumuskan strategi untuk meningkatkan partisipasi petani dalam penerapan pemupukan berimbang pada padi sawah. 
Berdasarkan uraian dan fokus masalah di atas penelitian ini menetapkan variabel yang diduga berhubungan dengan partisipasi, berupa variabel bebas atau yang mempengaruhi (1) faktor internal, yang terdiri atas; umur, tingkat pendidikan, pengalaman berusahatani, dan tingkat kepemilikan lahan usahatani, (2) faktor eksternal yang terdiri atas; ketersediaan sarana produksi, intersitas penyuluhan, dan ketersediaan sumber informasi. Sementara variabel terikat atau yang dipengaruhi adalah partisipasi.

\section{METODE PENELITIAN}

Penelitian dilaksanakan selama tiga bulan (April - Juni 2018) di dua Desa dan empat Kelompok Tani Kecamatan Sindangwangi Kabupaten Majalengka Jawa Barat. Penetapan desa dan kelompok secara purposive yaitu dipilih dengan pertimbangan pernah mengikuti program Sekolah Lapangan Pengelolaan Tanaman secara Terpadu (SL-PTT). Jumlah sampel dari empat kelompok sebanyak 48 orang, dengan rincian 13 orang dari Kelompok Tani Heuleut, 16 orang dari Mekar Harapan, 10 orang dari Sawah Maja, dan 9 orang dari Kelompok Teralame.

Data yang dikumpulkan terdiri atas data primer dan data sekunder. Data primer diperoleh secara langsung dari responden (petani) melalui wawancara langsung dengan menggunakan kuesioner tertutup yang telah diuji validitas dan reliabilitasnya. Sedangkan data sekunder diperoleh dari dokumen berupa laporan yang berasal dari Balai Penyuluhan Pertanian (BPP) dan kantor kecamatan setempat. Hasil uji reliabilitas instrument (kuesioner) diperoleh nilai Cronbach's Alpha 0.734 lebih besar dari 0.600 , yang berarti kuesioner yang dibuat layak dijadikan sebagai alat pengumpulan data (Sugiyono. 2011).

Analisis data dilakukan dengan dua cara yaitu, analisis statistic deskriptif, dan analisis hubungan Rank Speraman.

\section{HASIL DAN PEMBAHASAN}

\section{Hasil}

\subsection{Faktor Internal}

Keragaan responden berdasarkan kelompok umur, tingkat pendidikan, pengalaman berusahatani, dan luas lahan uashartani sangat bervariasi sebagaimana tersaji dalam tabel berikut:

\begin{tabular}{|c|c|c|c|}
\hline No & Kategori & Jumlah (Orang) & Persentase \\
\hline & \multicolumn{3}{|c|}{ Menurut Umur } \\
\hline 1 & Dewasa & 0 & 0 \\
\hline 2 & Tua & 10 & 20,8 \\
\hline \multirow[t]{2}{*}{3} & Lanjut & 38 & 79,2 \\
\hline & \multicolumn{3}{|c|}{ Pendidikan } \\
\hline 1 & SD & 30 & 62,5 \\
\hline 2 & SMP & 8 & 16,7 \\
\hline \multirow[t]{2}{*}{3} & SMA & 10 & 20,8 \\
\hline & \multicolumn{3}{|c|}{ Pengalaman } \\
\hline 1 & Baru & 0 & 0 \\
\hline 2 & Cukup Lama & 10 & 20,8 \\
\hline \multirow[t]{2}{*}{3} & Lama & 38 & 79,2 \\
\hline & \multicolumn{3}{|c|}{ Luas Lahan } \\
\hline 1 & Sempit & 46 & 95,8 \\
\hline 2 & Sedang & 1 & 2,08 \\
\hline \multirow[t]{2}{*}{3} & Luas & 1 & 2,08 \\
\hline & \multicolumn{3}{|c|}{ Kepemilikan } \\
\hline 1 & Milik & 42 & 87,5 \\
\hline 2 & Sewa & 6 & 12,5 \\
\hline
\end{tabular}

Berdasarkan data yang disajikan pada Tabel 1 diketahui, bahwa sebagian besar $(79.2 \%)$ responden termasuk kategori berumur lanjut ( $\geq 56$ tahun). Pada tingkat pendidikan sebagian besar responden $\quad(62.5 \%)$ berpendidikan Sekolah Dasar (SD), Sedangkan menurut pengalaman berusahatani termasuk kategori lama yaitu lebih dari 15 tahun (79.2\%). Sedangkan menurut luas kepemilikan dan status lahan sebagian besar $(95.8 \%)$ memiliki lahan yang sempit $\left(\leq 2.000 \mathrm{~m}^{2}\right)$ dan status kepemilikan adalah mayoritas (87.5\%) miliki sendiri.

\subsection{Faktor Eksternal}

Keragaan faktor eksternal dalam penelitian ini menunjukkan, bahwa sebagian besar responden atau berkisar $62.50 \%-77.08 \%$ berada pada kategori sedang pada semua indikator, sebagaimana tersaji pada tabel berikut: 


\begin{tabular}{|c|c|c|c|c|}
\hline \multirow[t]{2}{*}{ No } & \multirow[t]{2}{*}{ Indikator } & \multicolumn{3}{|c|}{ Kategori (\%) } \\
\hline & & Rendah & Sedang & Tinggi \\
\hline 1 & $\begin{array}{l}\text { Ketersediaan } \\
\text { Sarpras }\end{array}$ & 22.92 & 77.08 & 0.0 \\
\hline 2 & $\begin{array}{l}\text { Intensitas } \\
\text { Penyuluhan }\end{array}$ & 31.25 & 62.50 & 6.25 \\
\hline 3 & $\begin{array}{l}\text { Ketersediaan } \\
\text { Sumber } \\
\text { Informasi }\end{array}$ & 31.25 & 68.75 & 0.0 \\
\hline
\end{tabular}

\subsection{Partisipasi Penerapan \\ Pemupukan Berimbang}

Partisipasi responden dalam penerapan teknologi pemupukan berimbang pada pertanaman padi sawah di Kecamatan Sindangwangi sebagian besar $(62.5 \%)$ termasuk dalam ketegori rendah dan 37.5 persen termasuk dalam kategori cukup sebagaimana tersaji pada tabel berikut:

Tabel 2. Partisipasi Penerapan

Pemupukan

\begin{tabular}{cccc}
\hline No & Partisipasi & Jumlah (org) & Persentae \\
\hline 1 & Rendah & 30 & 62,5 \\
2 & Cukup & 18 & 37,5 \\
3. & Tinggi & 0 & 0 \\
& Jumlah & 48 & 100 \\
\hline
\end{tabular}

\subsection{Hubungan Faktor Internal dengan Partisipasi}

Hasil analisis korelasi Rank Spearman menunjukkan, bahwa tidak semua faktor internal berhubungan signifikan dengan partisipasi. Faktor internal yang memiliki hubungan signifikan adalah tingkat pendidikan, pengalaman berusahatani. Sementaraluas lahan dan status kepemilikan lahan berhubungan tidak signifikan, sebagaimana disajikan pada tabel berikut:

Tabel 3. Hubungan Faktor Internal dan Partisipasi

\begin{tabular}{lcc}
\hline \multirow{2}{*}{ Faktor Internal } & \multicolumn{2}{c}{ Tingkat Partisipasi } \\
\cline { 2 - 3 } & $\begin{array}{c}\text { Koefesien } \\
\text { Korelasi }\end{array}$ & $\begin{array}{c}\text { Tingkat } \\
\text { Signifikansi }\end{array}$ \\
\hline Umur & -0.042 & 0.775 \\
\hline Pendidikan & $0.541^{* *}$ & 0.000 \\
\hline Pengalaman UT & $-0.420^{* *}$ & 0.003 \\
\hline Luas Lahan & 0.140 & 0.308 \\
\hline
\end{tabular}

\subsection{Hubungan Faktor Eksternal dengan Partisipasi}

31 | Jurnal Agriekstensia Vol. 19 No. 1 Juli 2020
Selanjutnya hasil analisis korelasi Rank Spearman hubungan faktor eksternal dengan partisipasi dapat diketahui, bahwa tidak semua indikator berhubungan signifikan dengan partisipasi. Faktor ekternal yang memiliki hubungan signifikan dengan partisipasi adalah ketersediaan sarana produksi dan intensitas penyuluhan, sementara ketersediaan sumber informasi menunjukkan hubungan yang tidak nyata, sebagaimana disajikan pada tabel berikut:

Tabel 4. Hubungan Faktor Eksternal dengan Partisipasi

\begin{tabular}{|c|c|c|}
\hline \multirow[b]{2}{*}{$\begin{array}{c}\text { Faktor } \\
\text { Eksternal }\end{array}$} & \multicolumn{2}{|c|}{ Tingkat Partisipasi } \\
\hline & $\begin{array}{c}\text { Koefesien } \\
\text { Korelasi }\end{array}$ & $\begin{array}{c}\text { Tingkat } \\
\text { Signifikansi }\end{array}$ \\
\hline $\begin{array}{l}\text { Ketersediaan } \\
\text { Sarana Produksi }\end{array}$ & $0,512 * *$ & 0,000 \\
\hline $\begin{array}{l}\text { Intensitas } \\
\text { Penyuluhan }\end{array}$ & $0,182^{* *}$ & 0,215 \\
\hline $\begin{array}{l}\text { Ketersediaan } \\
\text { informasi }\end{array}$ & 0,134 & 0,365 \\
\hline
\end{tabular}

\section{Pembahasan}

Tingkat partisipasi petani responden (Tabel 2) dalam penerapan pupuk berimbang pada padi sawah di Kecamatan Sindangwangi mayoritas responden $(62.5 \%)$ termasuk kategori sedang, sehingga masih perlu ditingkatkan. Hasil ini dapat diduga karena kondisi internal dengan umur yang relative tua, pendidikan rendah (SD), dan luas kepemilikan lahan usahatani yang sempit. Hasil ini selaras dengan kesimpulan penelitian Suwarno (2002), Ramadoan (2013), Effendy dan Fajar (2020) yang menyimpulkan, bahwa karakteristik individu yang meliputi umur, pendidikan, pengalaman, kekosmopolitas, dan tanggungan keluarga berpengaruh terhadap partisipasi petani dalam kegiatan pertanian.

Hasil analisis hubungan berdasarkan Tabel 3 menunjukkan, bahwa faktor internal yang berhubungan dengan partisipasi direpresentasikan oleh tingkat pendidikan dan pengalaman berusahatani yang berhubungan secara negatif, sementara umur responden dan 
tingkat kepemilikan lahan usahatani berhubungan tidak nyata. Hasil ini dapat diinterpretasikan bahwa semakin tinggi pendidik petani akan menunjukkan partisipasi yang tinggi pula. Hasil ini selaras dengan hasil penelitian Effendy dan Badri (2020) yang menyimpulkan, bahwa tingkat pendidikan petani menentukan partisipasinya pada penerapan pupuk berimbang padi sawah di Kecamatan Sindangkasih Kabupaten Ciamis. Hasil ini senada juga dengan penelitian Suwiton dkk. (2014), yang menyimpulkan bahwa partisipasi anggota dalam penyusunan Rencana Defenitif Kelompok / Rencana Defenitif Kebutuhan Kelompok (RDK/RDKK) dipengaruhi oleh tingkat pendidikan anggota.

Pengalaman usahatani menunjukan hubungan negatif terhadap partisipasi artinya semakin berpengalaman petani, maka semakin rendah partisipasinya. Keadaan ini dapat dimengerti karena semakin berpengalaman seseorang, maka akan dijadikan pengalaman tersebut sebagai bekal untuk mencapai keberhasilan sehingga mereka yakin cukup dengan pengalaman yang telah dimiliki akan menjamin keberhasilan usahataninya. Hasil ini mendukung hasil penelitian Subagio dkk. (2008) yang menyatakan, bahwa kapasitas dan pengelaman petani ikut mempengaruhi keberhasilannya dalam berusahatani. Demikian juga Suwarno (2002) yang menyebutkan bahwa pengalaman seseorang mempengaruhi pengetahuan, keterampilan, dan sikap seseorang.

Analisis hubungan faktor eketernal terhadap partisipasi (Tabel 4) menghasilkan, bahwa partisipasi petani dalam penerapan pupuk berimbang berhubungan dengan ketersediaan sarana produksi dan intensitas kegiatan penyuluhan. Hasil ini mengindikasikan bahwa semakin tinggi tingkat ketersediaan sarana produksi maka akan semakin tinggi pula keterlibatan petani dalam penggunaan pupuk berimbang, hal ini dapat dipahami bahwa semakin tersedia sarana produksi akan semakin banyak kesempatannya untuk terlibat dan melakukan sesuatu. Hasil ini selaras dengan hasil penelitian Mario (2015) yang menyatakan bahwa sarana prasarana mempengaruhi keterlibatan petani, demikian juga Manik (2016) yang menyatakan hal yang sama.

$$
\text { Selanjutnya Tabel } 4 \text { juga }
$$

menunjukkan, bahwa intensitas penyuluhan berhubungan secara signifikan terhadap partisipasi petani dalam penerapan pupuk berimbang padi sawah. Hasil ini dapat diartikan bahwa kegiatan penyuluhan menjadi hal yang penting untuk mendorong keterlibatan atau partisipasi petani dalam suatu kegiatan atau menerapkan suatu inovasi. Dalam kegiatan penyuluhan tidak hanya terjadi proses pembelajaran yang mana akan meningkatkan pengetahuan, keterampilan, namun akan terjadi interaksi dua belah pihak antara penyuluh sebagai fasilitator, dinamisator dengan petani sebagai mitra belajar untuk mengatasi masalah yang mereka sedang hadapi. Hasil ini senada dengan penelitian Wahyuni (2003), Subagio (2008), Effendy dan Yunika (2020) yang menyatakan, bahwa kegiatan penyuluhan akan mempengaruhi partisipasi petani.

\section{Strategi Peningkatan Partisipasi}

Berdasarkan hasil dan pembahasan di atas dapat dirumuskan strategi untuk meningkatkan partisipasi dalam penggunaan teknologi pupuk berimbang, yaitu dimulai dengan tetap melaksanakan kegiatan penyuluhan secara terjadwal dengan materi sesuai kebutuhan petani, serta memperhatikan ketersediaan sarana produksi yang dibutuhkan.

\section{KESIMPULAN}

Kesimpulan penelitian ini adalah: (1) sebagian besar petani responden termasuk kategori usia lanjut (79.2\%), 
berpendidikan rendah atau SD (62.5\%), memiliki lahan usahatani sempit $(95.8 \%)$, namun memiliki pengalaman berusahatani termasuk dalam kategori lama (79.2\%), (2) faktor yang berhubungan nyata dengan partisipasi adalah tingkat pendidikan, pengalaman berusahatani, ketersediaan sarana produksi, dan intensitas penyuluhan, (3) strategi untuk meningkatkan partisipasi petani dalam penerapan teknologi pemupukan berimbang yaitu dengan mempertahankan kegiatan penyuluhan secara terjadwal terhadap petani yang memiliki tingkat pendidikan yang memadai dan dengan tetap memperhatikan ketersediaan sarana produksi.

\section{SARAN}

Hasil penelitian ini menyimpulkan masih rendahnya tingkat partisipasi petani dalam penerapan pupuk berimbang pada padi sawah dan tidak semua indikator yang terpilih menunjukkan hubungan yang signifikan terhadap partisipasi, oleh sebab itu perlu dilakukan penelitian serupa dengan meningkatkan jumlah responden dan jumlah kelompok tani serta terfokus pada indikator yang menunjukkan hubungan dan faktor-faktor lain yang belum terpilih.

\section{UCAPAN TERIMA KASIH}

Dengan selesainya artikel ini, penulis ingin menyampaikan ucapan terima kasih terumata kepada Saudara Ruwan Diantoro yang telah banyak membantu untuk menyelesaikan laporan penelitian. Ucapan yang sama juga ingin penulis sampaikan kepada Bapak Direktur Politeknik Pembangunan Pertanian Bogor yang telah memfasilitasi kegiatan ini melalui Unit Penelitian dan Pengabdian kepada Masyarakat.

\section{DAFTAR PUSTAKA}

Effendy, L dan Thopan. 2014. Partisipasi Anggota dalam Meningkatkan Kemampuan Kelompok Tani di Kelurahan Eka Marga Lubuk Linggau. Bogor: STPP. Jurnal Penyuluhan Pertanian Vol. 7 No. 2.

Effendy, L dan Yetsi. 2018. Motivasi Anggota Kelompok Tani dalam Peningkatan Fungsi Kelompok. Universitas Muhammadiyah. Palopo: Jurnal Ekonomi Pembangunan Vol. 4. No. 2.

Effendy, L. dan Carla Yunika. 2020. Model Peningkatan Minat Petani pada Penerapan Teknologi Tanam Jajar Legowo Padi Sawah di Kacamatan Cikoneng Ciamis Agritexts: Journal of Agricultural Extension (UNS), Vol. 48 (2) Maret 2020

Effendy, L dan Sudiro. 2020. Model

Peningkatan Partisipasi Petani dalam Penerapan Pemupukan Berimbang Padi Sawah di Kecamatan Cikoneng. International Journal Arts and Social Sciens (IJASS), Vol 3 Issue (1 JanFeb 2020)

Effendy, L.\& Siska Dinia Pratiwi. 2020. Tingkat Adopsi Teknologi Sistem Tanam Jajar Legowo Padi Sawah di Kecamatan Cigasong Kabupaten Majalengka. Jurnal Agrica Ekstensia. Vo. 14 (1). Juni 2020

Effendy, L dan Badri, 2020. TModel Peningkatan Kapasitas Petni pada Penerapan Pemupukan Berimbang Padi Sawah di Kecamatan Sindangkasih Ciamis JOURNAL OF SOCIAL SCIENCE (JSS)

Effendy, L. dan Reza Oktaviansyah. 2019. Model Peningkatan Partisipasi Petani dalam Penggunaan Varietas Unggul Baru Padi Sawah di Kecamatan Sindangkasih Kabupaten Ciamis. Journal of Agriculture 
Extension Nigerian. Vol. 9 (1) Feb 2020

Kartono. 2009. Persepsi Petani dan Penerapan Inovasi Pengelolaan Tanaman dan Sumber Daya Terpadu Padi Sawah di Lokasi Prima Tani Kabupaten Serang. [Tesis] Bogor (ID): Institut Pertanian Bogor

Kusmiyati, Dewi. 2015. Perilaku Petani Terhadap Resiko Usahatani Kedelai di Kecamatan Jawai Selatan, Kabupaten Sambas. Jurnal Pertanian Vo. 3. No.2.

Ramadoan, S. 2013. Peran PKSM dalam Meningkatkan Fungsi Kelompok Tani dan Partisipasi Masyarakat di Kabupaten Bima NTB. Jurnal Penelitian Sosial dan Ekonomi Kehutanan 10 (3): 199 - 210

Rogers, EM. 2003. Diffusion of Inovations. New York (US): The Free Press.

Margono Slamet. 2003. Membentuk Pola Perilaku Manusia Pembangunan. Diedit oleh Ida Yustina dan Ajat Sudradjat. Bogor: IPB Press.

Subagio, H., P.S. Asngari, P. Tjitropranoto, dan D. Susanto. 2008. Kapasitas Petani dalam Mewujudkan Keberhasilan Usahatani. Kasus Petani Sayuran dan Padi di Kabupaten Malang dan Pasuruan. Jurnal Penyuluhan Vol. 4 No. 1. Bogor

Sugiyono. 2012. Metode Penelitian Administrasi. R \& D. Bandung. Alfabeta

Suwiton, Lukman Effendy, dan Elih Juhdi Muslihat. 2014. Partisipasi Anggota Kelompok Tani dalam Penyusunan Rencana Definitif

34 | Jurnal Agriekstensia Vol. 19 No. 1 Juli 2020
Kebutuhan Kelompok Di Gorontalo (Jurnal Penyuluhan Pertanian, Volume: 9 Nomor: 1 Tahun 2014

Thamrin, M. S. Herman dan Fahrul Hanafi. 2014. Pengaruh Ekonomi Terhadap Pendapatan Petani Pinang. Jurnal Pertanian 5(2): 45-57

Wibowo, S dan Musyadar. 2014. Hubungan Metode Penyuluhan dengan Tingkat Keberhasilan Pendekatan PTT Padi Sawah di Kecamatan Woluwaru Kabupaten Ende. Jurnal Pertanian 5(2): 58-72 